\title{
The 2010-2011 drought in the Horn of Africa in ECMWF reanalysis and seasonal forecast products
}

Article

Published Version

Dutra, E., Magnusson, L., Wetterhall, F., Cloke, H. L., Balsamo, G., Boussetta, S. and Pappenberger, F. (2013) The 2010-2011 drought in the Horn of Africa in ECMWF reanalysis and seasonal forecast products. International Journal of Climatology, 33 (7). pp. 1720-1729. ISSN 0899-8418 doi: https://doi.org/10.1002/joc.3545 Available at https://centaur.reading.ac.uk/29718/

It is advisable to refer to the publisher's version if you intend to cite from the work. See Guidance on citing.

To link to this article DOI: http://dx.doi.org/10.1002/joc.3545

Publisher: John Wiley \& Sons

All outputs in CentAUR are protected by Intellectual Property Rights law, including copyright law. Copyright and IPR is retained by the creators or other copyright holders. Terms and conditions for use of this material are defined in the End User Agreement. 


\section{CentAUR}

Central Archive at the University of Reading

Reading's research outputs online 


\title{
The 2010-2011 drought in the Horn of Africa in ECMWF reanalysis and seasonal forecast products
}

\author{
Emanuel Dutra, ${ }^{a *}$ Linus Magnusson, ${ }^{a}$ Fredrik Wetterhall, ${ }^{a}$ Hannah L. Cloke, $,{ }^{a}, b$ \\ Gianpaolo Balsamo, ${ }^{\mathrm{a}}$ Souhail Boussetta ${ }^{\mathrm{a}}$ and Florian Pappenberger ${ }^{\mathrm{a}}$ \\ ${ }^{a}$ European Centre for Medium-Range Weather Forecasts, Reading, UK \\ ${ }^{\mathrm{b}}$ Department of Geography, King's College London, London, UK
}

\begin{abstract}
This study evaluates the use of European Centre for Medium-Range Weather Forecasts (ECMWF) products in monitoring and forecasting drought conditions during the recent 2010-2011 drought in the Horn of Africa (HoA). The region was affected by a precipitation deficit in both the October-December 2010 and March-May 2011 rainy seasons. These anomalies were captured by the ERA-Interim reanalysis (ERAI), despite its limitations in representing the March-May interannual variability. Soil moisture anomalies of ERAI also identified the onset of the drought condition early in October 2010 with a persistent drought still present in September 2011. This signal was also evident in normalized difference vegetation index (NDVI) remote sensing data. The precipitation deficit in October-December 2010 was associated with a strong La Niña event. The ECMWF seasonal forecasts for the October-December 2010 season predicted the La Niña event from June 2010 onwards. The forecasts also predicted a below-average October-December rainfall, from July 2010 onwards. The subsequent March-May rainfall anomaly was only captured by the new ECWMF seasonal forecast system in the forecasts starting in March 2011. Our analysis shows that a recent (since 1999) drying in the region during the March-May season is captured by the new ECMWF seasonal forecast system and is consistent with recently published results. The HoA region and its population are highly vulnerable to future droughts, thus global monitoring and forecasting of drought, such as that presented here, will become increasingly important in the future. Copyright (c) 2012 Royal Meteorological Society
\end{abstract}

KEY WORDS drought; monitoring; seasonal forecast; east Africa; precipitation; reanalysis

Received 1 March 2012; Revised 17 May 2012; Accepted 17 June 2012

\section{Introduction}

Rainfall plays a major role in determining agricultural production in areas dependent on traditional rainfed agriculture, such as the Horn of Africa (HoA) (Haile, 2005), and a persistent anomaly has severe impacts on the population. It is estimated that the recent 2010-2011 drought in the HoA affected approximately 12 million people. The drought in the region has been estimated by some sources the worst in the last 60 years (Loewenberg, 2011). Although the main trigger of the crisis was the drought, other factors, including conflicts, population displacement and an increase in food and fuel prices led to a serious humanitarian crisis (http://reliefweb.int/hornafrica-crisis2011).

This study presents an evaluation of the European Centre for Medium-Range Weather Forecasts (ECMWF) products in monitoring and forecasting drought conditions in the 2010-2011 event in the HoA, and in general during the rainy seasons. The monitoring of the drought is evaluated through a comparison of the ERA-Interim reanalysis (ERAI; Dee et al., 2011) precipitation against

* Correspondence to: E. Dutra, ECMWF Shinfield Park, Reading RG2 9AX, UK. E-mail: emanuel.dutra@ecmwf.int several global datasets based on observations. Soil moisture, widely used as a drought indicator since it integrates precipitation anomalies in time (e.g. Dutra et al., 2008; Sheffield and Wood, 2008), is also evaluated through the ERAI soil moisture anomalies. The normalized difference vegetation index (NDVI) from the moderate resolution imaging spectroradiometer (MODIS) is used as an independent source to assess the vegetation stress during the drought period. The seasonal precipitation forecasts were evaluated (against different verification sources) by analyzing the skill of two versions of the ECMWF seasonal forecast systems. Furthermore, a recent (since 1999) drying of the March-May precipitation in the region, documented by Lyon and DeWitt (2012) is assessed in historical seasonal forecasts. The different datasets used in this study are described in Section 2, the results are presented in Sections 3 (monitoring with ERAI) and 4 (forecasting with seasonal forecasts) and summarized in Section 5

\section{Data}

The HoA region is defined in this study as the land area between $3{ }^{\circ} \mathrm{S}$ to $12 \mathrm{~N}^{\circ}$ and $40^{\circ} \mathrm{E}$ to $52^{\circ} \mathrm{E}$ (see box 
in Figure 4), including Somalia, central and southeastern Ethiopia (east of the Ethiopian Highlands), accounting for approximately $1.2 \times 10^{6} \mathrm{~km}^{2}$ [similar to the HoA sub-region used by Mariotti et al. (2011)]. Precipitation in the HoA region is characterized by two rainy seasons, March-May (MAM, 'long rains') with higher intensity and a second of shorter duration in October-December (OND, 'short rains').

The observation-based precipitation datasets in this study include: (1) the Global Precipitation Climatology Centre version 6 (GPCC; Rudolf and Schneider, 2005; Schneider et al., 2011; http://gpcc.dwd.de); (2) the Climate Prediction Center (CPC) Merged Analysis of Precipitation (CMAP; Xie and Arkin, 1997); (3) the Global Precipitation Climatology Project version 2.1 (GPCP21; Huffman et al., 2009) and version 2.2 (GPCP22; Huffman et al., 2011) and (4) the Climate Research Unit version 3.1 [CRU, updated from Mitchell and Jones (2005)]. GPCC and CRU are only based on rain gauges, while GPCP and CMAP blend data from a variety of satellites and gauges. The datasets provide monthly means of precipitation which span 1979 (or before) to December 2008 (CRU), September 2009 (GPCP21 and CMAP) and December 2010 (GPCC and GPCP22).

The variables analyzed for the drought monitoring were ERAI output, the latest global atmospheric reanalysis produced by ECMWF which extends from 1 January 1979 to present date. See Dee et al. (2011) for detailed descriptions of the atmospheric model used in ERAI, the data assimilation system, the observations used and various performance aspects. The ERAI configuration has a spectral T255 horizontal resolution (about $0.7 \times 0.7$ in the grid-point space) with 60 model levels. Unlike the other datasets used in this study, ERAI does not make use of rainfall measurements. Rather, 3hourly ERAI precipitation estimates are produced by $12 \mathrm{~h}$ model integrations starting at 00UTC and 12UTC daily from initial conditions provided by the data assimilation system. These short-range forecasts are therefore mainly constrained by the analysis of upper-air observations of temperature and humidity, from satellites and in situ instruments. Soil moisture and $2 \mathrm{~m}$ temperature (T2M) were taken from the 6-hourly surface analysis of ERAI (Mahfouf et al., 2000). Albergel et al. (2011) showed that ERAI has a good skill in capturing the soil moisture variability (using observations across the world). Additionally, we also analyzed the monthly NDVI from MODIS (Huete et al., 2002) at $0.05^{\circ}$ resolution (product MOD13C2), available from February 2000 to December 2011. NDVI is used as an independent data source to monitor the vegetation stress during the drought which is closely related with soil moisture anomalies (Peled et al., 2010).

ECMWF seasonal precipitation forecasts, based on an atmosphere-ocean coupled model, were used for the drought forecasting. In this article, we evaluate System 3 (S3; Anderson et al., 2007; Stockdale et al., 2011) that has been in operation since 2006 and will be discontinued during 2012, and its successor, the recently implemented
System 4 (S4; Molteni et al., 2011). The horizontal resolution of the atmospheric model is TL159 (about $1.125^{\circ}$ in the grid-point space) with 62 vertical levels in S3 and TL255 (about $0.7^{\circ}$ in the grid-point space) with 91 vertical levels in S4. The ocean model has 29 and 42 vertical levels in S3 and S4, respectively, with a horizontal resolution of approximately $1^{\circ}$ in both systems. The seasonal forecast generates 41 (S3) and 51 (S4) ensemble members in real-time with 25 years (S3, 1981-2005, 11 ensemble members) and 30 years (S4, 1981-2010, 15 ensemble members) of back integrations (hindcasts), with a lead time of 7 months, including the month of issue. For this application, we extended the hindcast period of S3 5 years by randomly sampling 11, out of 41 , ensemble members from the real-time forecasts since 2006 to 2010. S3 and S4 could then be evaluated over the same 30 years hindcast period, only differing in the number of ensemble members, 11 and 15 for S3 and S4, respectively. Molteni et al. (2011) presented an overview of the model biases and forecast scores of S3 and S4.

\section{Monitoring}

The ERAI mean annual cycle of precipitation over the HoA is comparable with the observation-based global datasets (Figure 1). All the datasets agree on the onset and the end of the rainy seasons, but differ in their intensity. ERAI has the highest peak values in both seasons, suggesting an overestimation of intensity in the reanalysis product. The challenges of representing the mean annual cycle of precipitation in the HoA in atmospheric models are well known (Mariotti et al., 2011). However, it should also be highlighted that the global observation-based precipitation products used for comparison display a large uncertainty in the representation of the mean annual cycle of precipitation. Furthermore, the number of rain gauges entering the datasets decreased though time in the region. For example, in GPCC, there was a drop in the number of stations from approximately 40 to 15 to 5 in the periods 1979 to 1990,1992 to 2005 and 2005 to 2010 , respectively.

The interannual variability of the OND and MAM precipitation [Figure 1(b) and (c)] and the anomaly correlation coefficient (ACC) among the different products (see Table I) highlight the nature and variability of precipitation in the region. All datasets, including ERAI, are in good agreement during the OND season (ACC $>0.8$ in Table I), although ERAI contains a slight positive trend. On the other hand, during MAM, the 'long rains' season, there is a drop in the correlations between the datasets, especially in ERAI from significant values around 0.85 to not significant values below 0.35; ERAI does not represent the interannual variability and has a low (not significant) ACC. The ERAI problems during MAM are clearly illustrated in Figure 1(b), where both GPCC and GPCP are very similar, as expected since they share similar data over land, presenting a negative trend, in particular since 


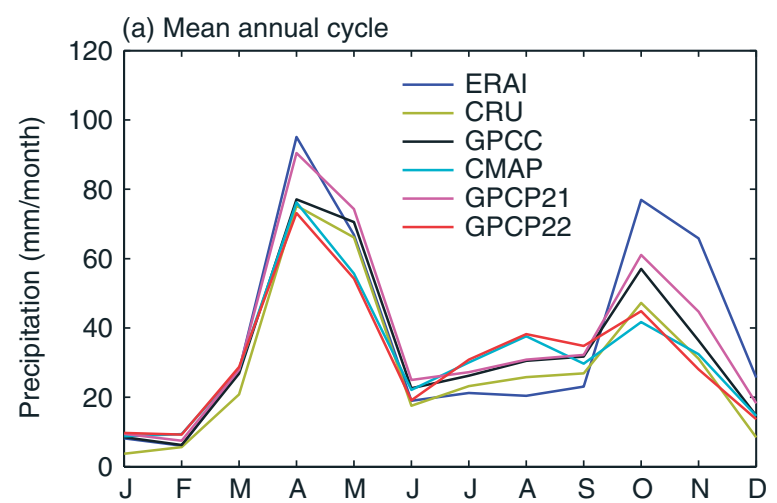

(b) March-May

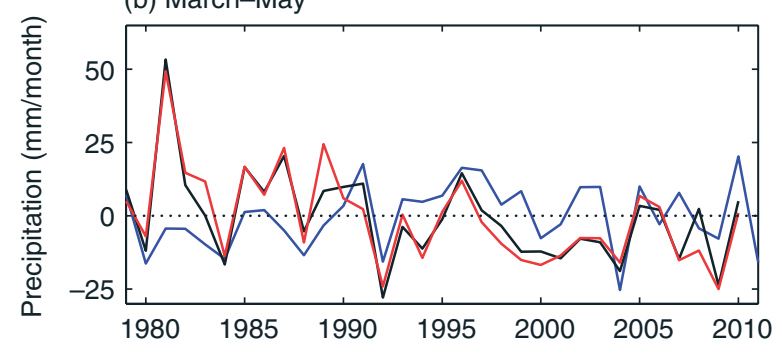

(c) October-December

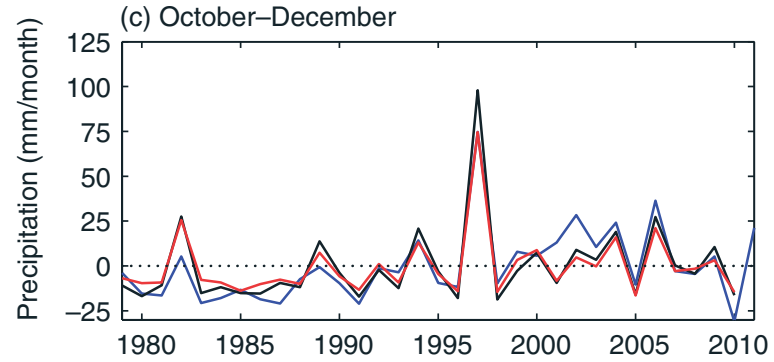

Figure 1. (a) Mean annual cycle of the different precipitation products averaged over the HoA: ERAI (blue), CRU (green), GPCC (black), CMAP (cyan), GPCP21 (magenta) and GPCPv22 (red). The mean annual cycle was calculated for the common period January 1979 to December 2008. Seasonal precipitation anomalies during MAM (b) and OND (c) calculated as departures from the 1979-2010 mean.

1999 (Williams and Funk, 2011; Lyon and DeWitt, 2012). ERAI does not capture this negative trend and has a lower interannual variability than the remaining datasets. However, ERAI captured the 2011 MAM-negative anomaly, as well as OND 2010. Dee et al. (2011) found that ERAI overestimates precipitation over central Africa (and in general over the tropical oceans), along with an excessive decadal decrease of precipitation in the region, associated with a warm bias in the model and changes in data coverage in the last decade. The problems found in ERAI over the HoA, especially during MAM, have not been previously documented. They may be related with changes in the data coverage and observations entering the data assimilation that masked the trend found in the remaining datasets. These results show that the use of ERAI for monitoring purposes should be carefully assessed against independent datasets, suited to the particular application and region of interest.

The temporal evolution of the ERAI anomalies of precipitation and soil moisture from January 2010 to December 2011 indicates a severe drought situation in
Table I. Seasonal anomaly correlations between the different precipitation products averaged over the HoA for the MAM season (upper diagonal) and OND season (lower diagonal).

Significant correlations $(P<0.01)$ are denoted with*.

\begin{tabular}{lllllll}
\hline & ERAI & CRU & GPCC & CMAP & GPCP21 & GPCP2.2 \\
\hline ERAI & & 0.35 & 0.30 & 0.34 & 0.30 & 0.17 \\
CRU & $0.80^{*}$ & & $0.78^{*}$ & $0.79^{*}$ & $0.80^{*}$ & $0.79^{*}$ \\
GPCC & $0.89^{*}$ & $0.87^{*}$ & & $0.79^{*}$ & $0.96^{*}$ & $0.93^{*}$ \\
CMAP & $0.85^{*}$ & $0.85^{*}$ & $0.95^{*}$ & & $0.81^{*}$ & $0.81^{*}$ \\
GPCP21 & $0.91^{*}$ & $0.87^{*}$ & $1.00^{*}$ & $0.95^{*}$ & & $0.96^{*}$ \\
GPCP22 & $0.88^{*}$ & $0.84^{*}$ & $0.99^{*}$ & $0.94^{*}$ & $0.99^{*}$ & \\
\hline
\end{tabular}

late 2010 to early 2011 (Figure 2). MAM 2010 was wetter than normal, while the OND 2010 precipitation was below normal in both ERAI and GPCP22. These results are consistent with the reported anomalies in the state of climate in 2010 (Blunden et al., 2011). The soil moisture in the top metre (SM1) [Figure 2(c)] represents water availability to vegetation/crops (root zone), essential in the HoA region because of reliance on traditional rainfed agriculture (Haile, 2005). The top metre soil moisture in ERAI started in an anomalous dry condition early in October 2010 and continued below the 10th percentile until September 2011. The SM1 anomaly is consistent with the NDVI anomalies [Figure 2(f)] pointing to a long-term vegetation stress in the region. The soil moisture depletion and the impact on vegetation were further enhanced with the warm temperature anomalies [Figure 2(e)] (increasing the atmospheric local water demand). The full column soil moisture [SMF, Figure 2(d)] was depleted rapidly during the October-December dry season, dropping below the 10th percentile in November 2010 and did not recover to normal conditions until October 2011.

The spatial pattern of precipitation anomalies in ERAI during OND 2010 agrees with GPCP22 (Figure 3), with a dry anomaly over the northwestern Indian Ocean, extending to eastern Africa and also over the central Pacific. However, there is also a wet anomaly in the eastern Indian Ocean. These anomalies are consistent with the sea surface temperature (SST) anomalies (see Figure 4(a)) corresponding to a La Niña event. This influence of El Niño-Southern Oscillation (ENSO) on east African rainfall has been widely documented (e.g. Camberlin et al., 2001; Nicholson and Selato, 2000). Furthermore, the SM1 and NDVI anomalies during OND 2010 (Figure 4) also point to east Africa being dry and northwestern Australia and southern Indian Ocean being wet.

During MAM 2011, the pattern of the precipitation anomalies in ERAI (Figure 3(c)) is consistent with the results presented by Lyon and DeWitt (2012) based on merged analysis of station rainfall observations and satellite estimates (Janowiak and Xie, 1999). The dry anomaly in east Africa can also observed over the central and southern Indian Ocean, west-central Pacific and southwest Africa, while there is a wet anomaly in 

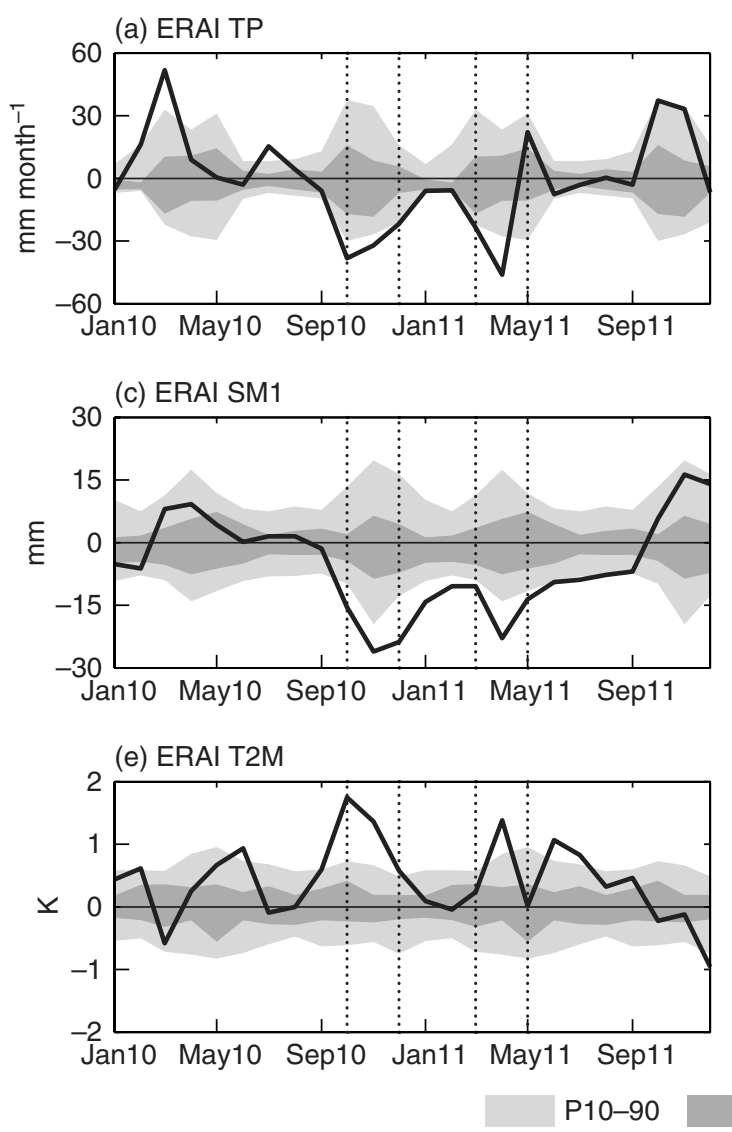

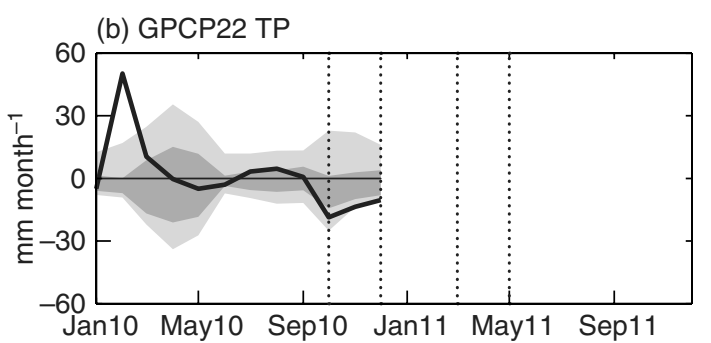

(d) ERAI SMF
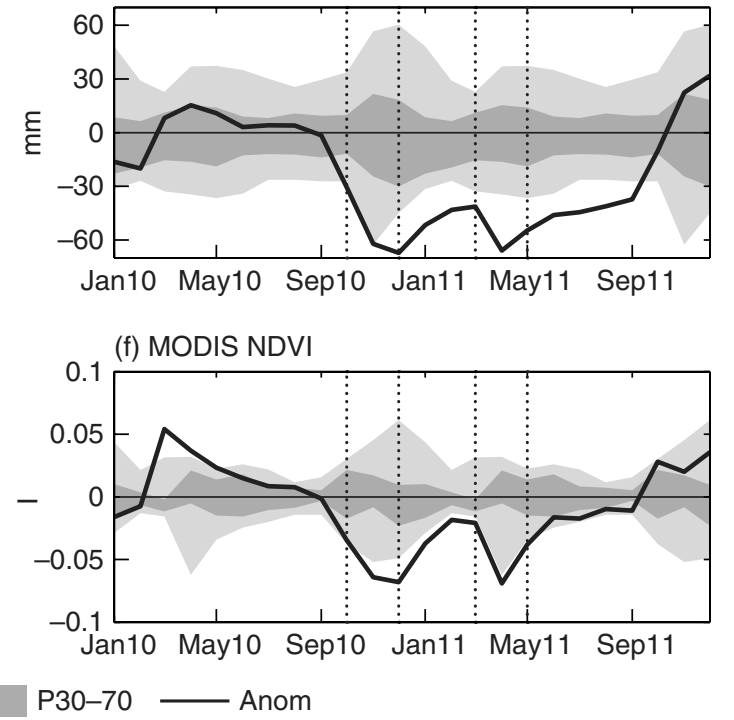

Figure 2. 2010-2011 anomalies of precipitation from ERAI (a) and GPCPv2.2 (b), ERAI soil moisture 0-1 m (c) and 0-2.89 m (d), ERAI 2-metre temperature (e) and MODIS NDVI (f). The time series represent averages in the HoA of the anomaly (solid black), and the climatological distribution (1979-2010 for a-e and 2000-2011 for (f) between percentiles 10 to 90 (light gray), and percentiles 30 to 70 (darker gray). Note that GPCP22 (b) is only available until December 2010.

the western tropical Pacific. The ERAI SM1 and NDVI anomalies patterns during MAM 2011 (Figure 4) are also consistent with the precipitation anomalies. Despite the limitations of ERAI precipitation during the MAM season in the HoA, described earlier, the 2011 event was captured both in terms of precipitation and soil moisture anomalies. These results highlight the role of soil moisture in monitoring droughts associated with the temporal integration of precipitation (forcing) and evaporation (demand) anomalies.

\section{Seasonal forecasts}

Firstly, the skill of S3 and S4 precipitation forecasts for the OND and MAM seasons was analyzed and evaluated in terms of the ACC for the ensemble mean and the continuous rank probability skill score (CRPSS). The continuous rank probability score (CRPS, see Hersbach (2000)) is a development of the ranked probability score. It can be interpreted as the integral of the Brier Score over all possible threshold values of the parameter under consideration. In deterministic forecasts, the CRPS is reduced to the mean absolute error. Since the CRPS is not a normalized measure, we evaluate the CRPSS. In the skill score calculation, the reference forecast was taken from the verification dataset as a random sample of different years, to produce a climatological forecast with the same ensemble size as the system that is verified. The CRPS of the reference forecast was evaluated as the mean of 100 bootstrapped reference forecasts to avoid sampling errors and to make the reference forecast more robust. In the previous section, it was found that the five observational-based global datasets of precipitation (CRU, GPCP21/22, CMAP and GPCC) could represent the interannual variability of precipitation the HoA region during the OND and MAM seasons (see Table I). However, the ACC between the datasets varies from 0.78 to 1 . Since we do not have access to a dataset based only on rain gauges with a detailed coverage of the region (if it exists) which could serve as ground-truth for the seasonal forecast verification, the ACC and CRPSS were calculated for each of the different precipitation datasets. ERAI was also included as a verification dataset, despite the problems of the MAM interannual variability.

The ACC and CRPSS of both S3 and S4 for the forecasts valid in OND with different lead times (from June to October) show a consistent and skillful prediction of the precipitation anomalies in the region (Figure 5). In both ACC and CRPSS, S4 has higher skill than S3 considering the different verification datasets and lead times, except for the forecasts starting in September where S3 outperforms S4. The uncertainty associated 

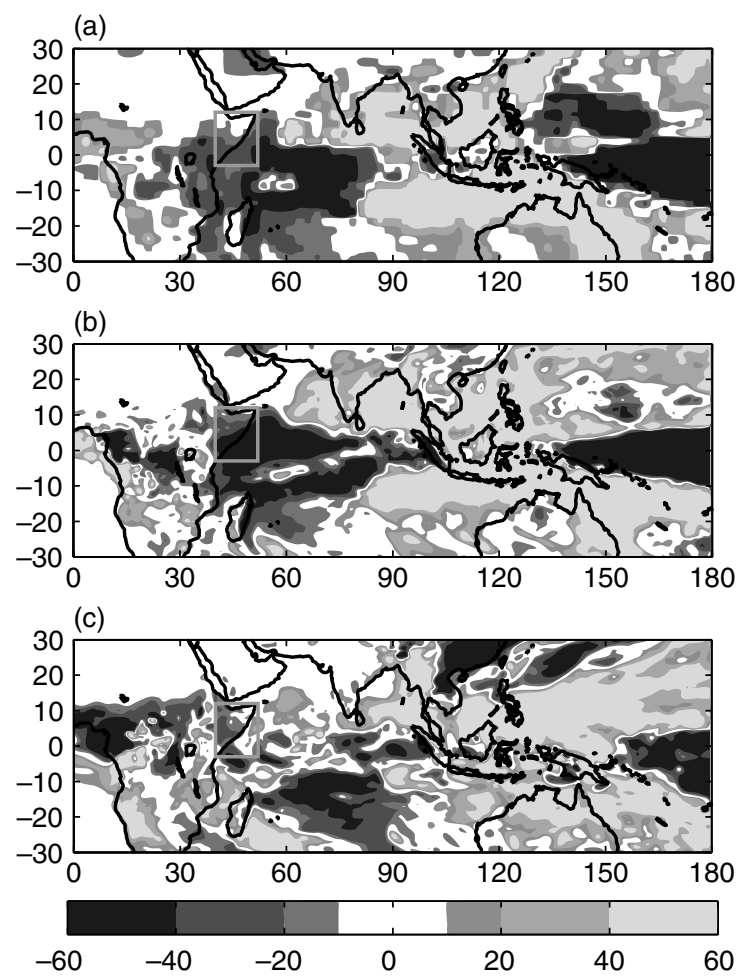

Figure 3. Spatial patterns of the precipitation anomalies (mm month-1) during OND 2010 in GPCP22 (a) and ERAI (b) and during MAM 2011 in ERAI (c). The anomalies were taken in respect to the 1979-2010 climate.

with choosing different verification datasets is small regarding the $\mathrm{ACC}$, and the $\mathrm{ACC}$ tends to be similar when using GPCC, CMAP, GPCP21 and GPCP22. There is a larger uncertainty in the CRPSS. This is mainly associated with the reduced size of the seasonal forecast ensembles in the hindcast period (11 members in S3 and 15 members in S4) which has the effect of an underestimation of the variability of the datasets because of a limited sample size. Furthermore, reducing the number of ensemble members of S4 from 15 to 11 (as used in S3) has a reduced impact in the skill scores when compared with the uncertainty due to the use of different verification products (not shown). Both CRPSS and ACC tend to be lower if ERAI is used as a verification dataset in comparison with other datasets for most of the forecast lead times. This result is unexpected and is associated with an artificial positive trend of ERAI OND precipitation [see Figure 1(c)]. When the OND ERAI precipitation is detrended prior to the verification (ERAId, Figure 5), the skill scores are similar to those evaluated with the different observation-based datasets. This signal is also found when calculating the correlation between the OND precipitation in the HoA and the SST anomalies in the pacific for the Nino3.4 region [Figure 6(a)]. The ACC are about 0.6 for GPCC, CMAP, GPCP21 and GPCP22 and ERAId, while lower for ERAI and CRU. ACC is a measure of the teleconnection strength between ENSO and the east African precipitation in OND, which is also present in S3 and S4 [Figure 6(b)] at different lead times.

Neither S3 nor S4 forecasts show any skill for MAM at the different lead times (Figure 7), except for the S4 forecasts starting in March. These results were expected, since the MAM precipitation in the HoA as a whole does not exhibit very strong relationships with any large-scale climate anomaly (Camberlin and Philippon, 2002). For example, there is no correlation between Nino3.4 SSTs and the HoA precipitation (observation-based datasets) in MAM [Figure 6(c)]. However, in both S3 and S4, the HoA precipitation in MAM shows significant correlations with Nino3.4. This indicates that the MAM precipitation over the HoA is partially controlled by ENSO in both
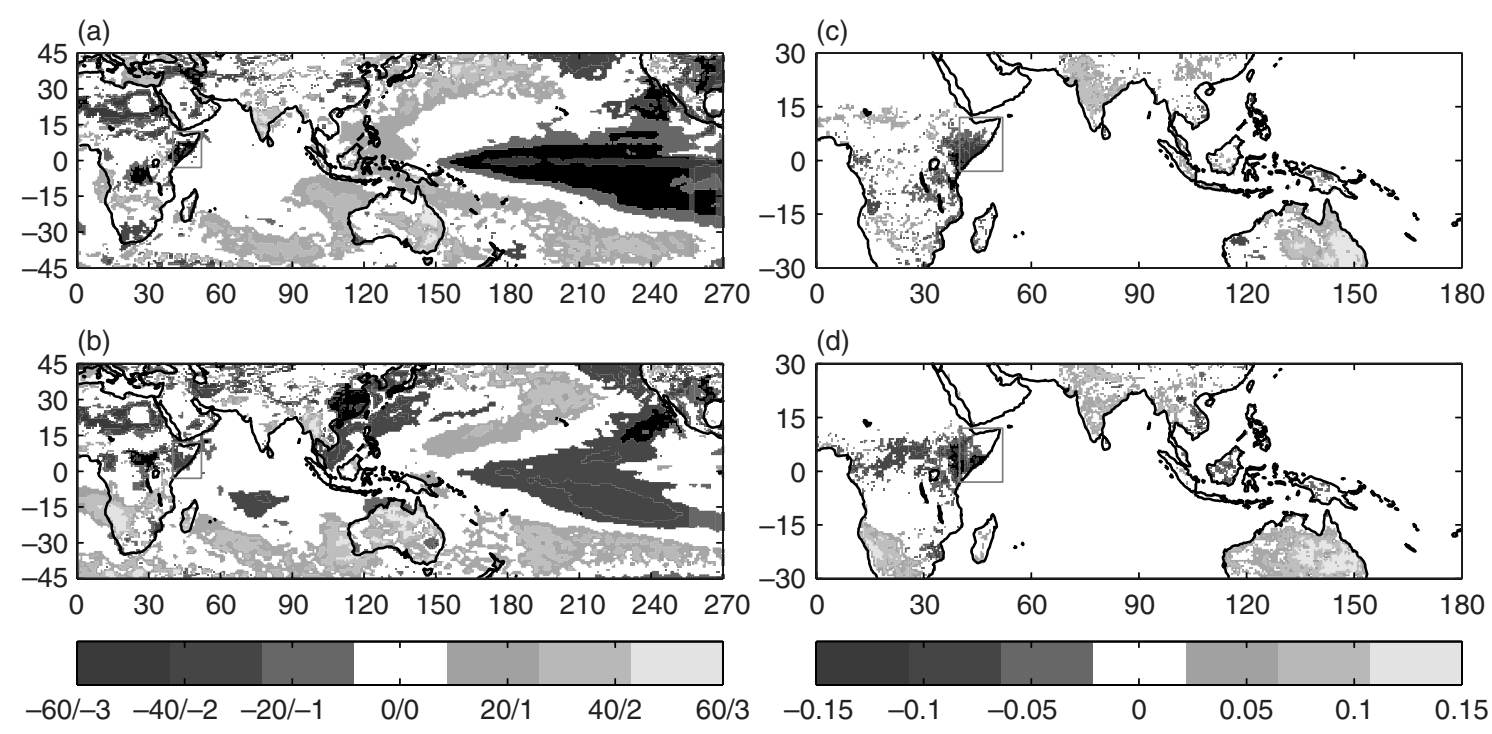

Figure 4. Spatial patterns of the top first meter soil moisture anomalies ( $\mathrm{mm}$ - land only) and sea surface temperature SST (K - ocean only) in ERAI during OND 2010 (a) and MAM 2011 (b). The anomalies are relative to the 1979-2010 climate. The soil moisture and SST anomalies share the same color bar from -60 to $60 \mathrm{~mm}$ for soil moisture and -3 to $3 \mathrm{~K}$ for SST. Spatial patterns of the MODIS NDVI anomalies during OND 2010 (c) and MAM 2011 (d). The anomalies are relative to the 2000-2011 climate. 

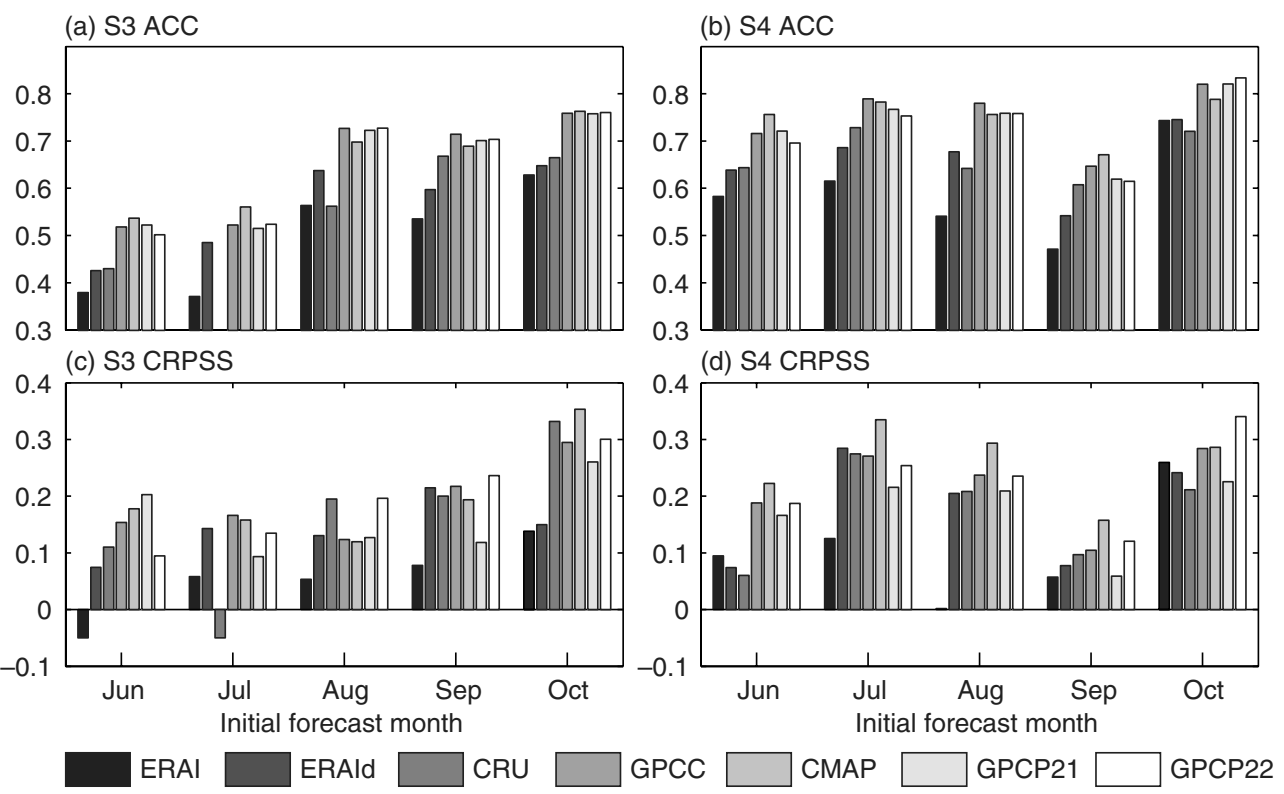

Figure 5. Skill of seasonal forecasts of precipitation for OND in the HoA for S3 (a and c) and S4 (b and d). The skill measures are the anomaly correlation coefficient (ACC; $\mathrm{a}$ and $\mathrm{b}$ ) and the continuous rank probability skill score (CRPSS; $\mathrm{c}$ and $\mathrm{d}$ ). The seasonal forecasts were verified against different datasets (bars in the panels): ERAI, ERAId, CRU, GPCC, CMAP, GPCP21 and GPCP22. Only significant $(P<0.05)$ ACC are displayed and CPRSS values equal or lower than 0 are set to -0.05 . The verification was performed over the entire length of each dataset.
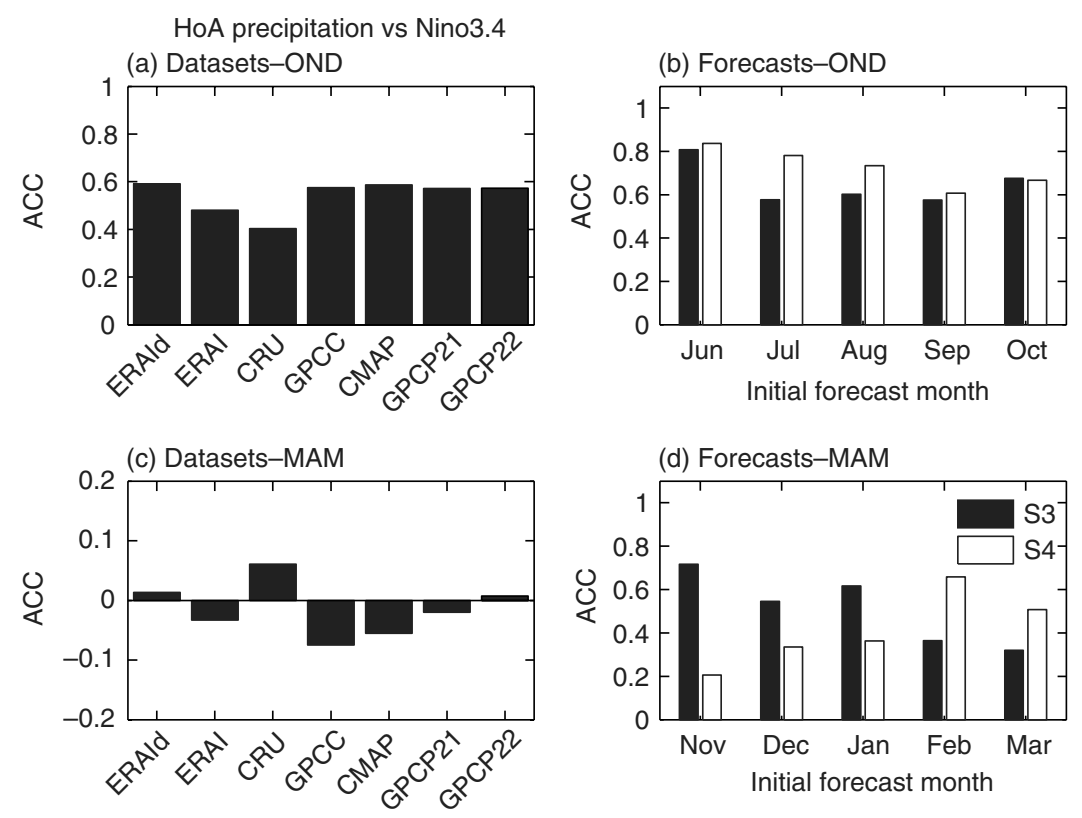

Figure 6. Correlation between precipitation in the HoA (different products) and Nino3.4 (derived from ERAI SST) for the OND (a) and MAM (c) seasons. Correlation between the precipitation in the HoA and Nino3.4 in the seasonal forecasts (S3 white, S4 black) valid for the OND (b) and MAM (d) seasons, as a function of the initial forecast month.

systems (S3 and S4), while such relation is not present in reality.

The time series of seasonal precipitation from GPCP22 and the ensemble mean of S3 and S4 for OND and MAM (Figure 8) further illustrate the different behaviour of the seasonal forecasts in predicting precipitation anomalies in the HoA. The forecasts and GPCP22 in Figure 8 are presented as $\mathrm{z}$-scores (removed mean and divided by standard deviation). This representation can be interpreted as a systematic bias correction of the forecast mean and variability in order to match the verification dataset. During OND, there is a good agreement of the interannual variability of S3 and S4 in comparison with GPCP22, and both systems predicted a dry OND from July 2010 onwards [Figure 8(c)]. During MAM, there is no apparent relation between GPCP22 and the seasonal forecasts [Figure 8(b)], and the forecasts from November 2010 to February 2011 had no anomalous signal (model climate) for MAM 2011. However, the forecasts issued in March 2011 had a dry signal for the MAM season 
(a) S3 ACC

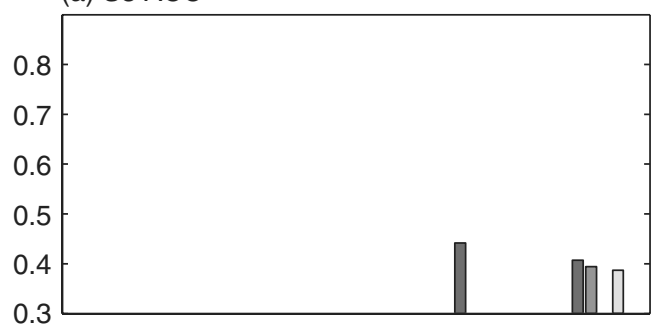

(c) S3 CRPSS

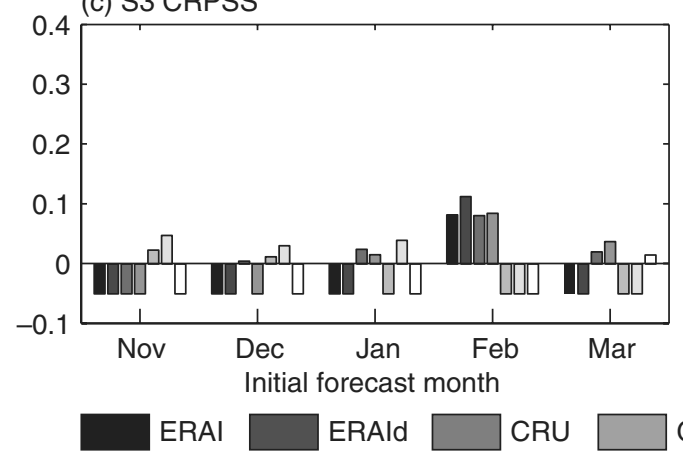

(b) S4 ACC

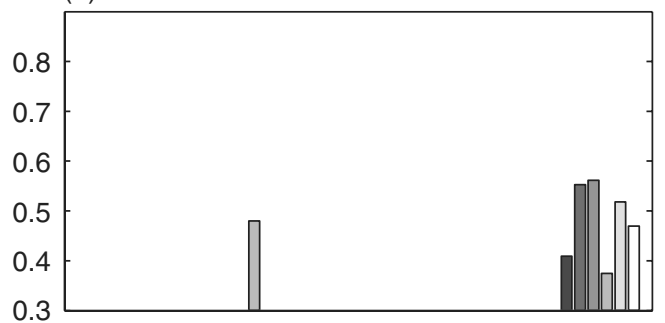

(d) S4 CRPSS

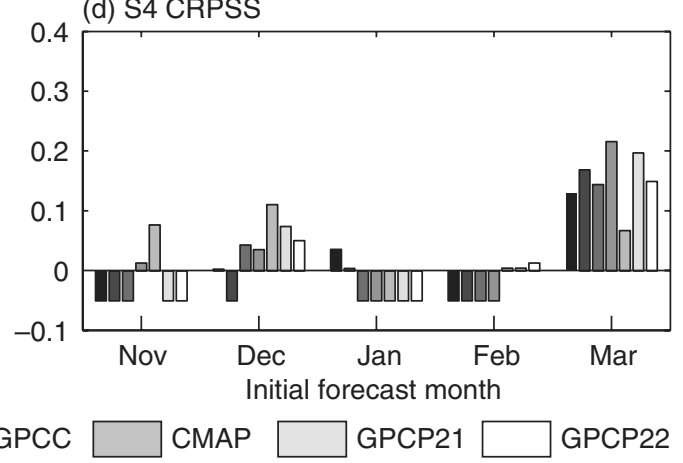

Figure 7. As Figure 5 but for the seasonal forecasts valid for MAM.

(a) Oct-Dec

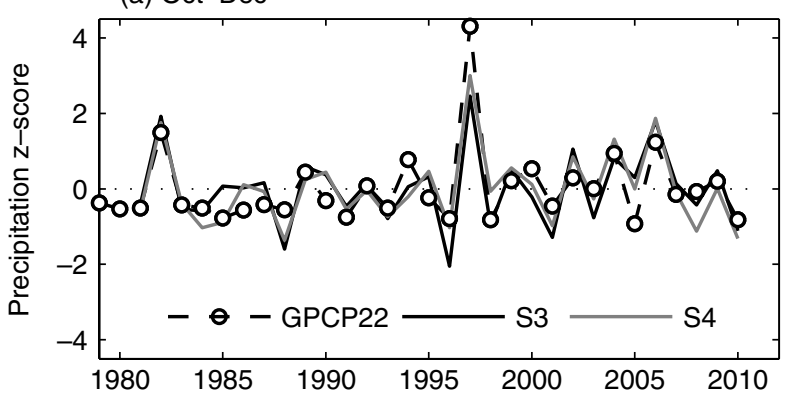

(b) Mar-May

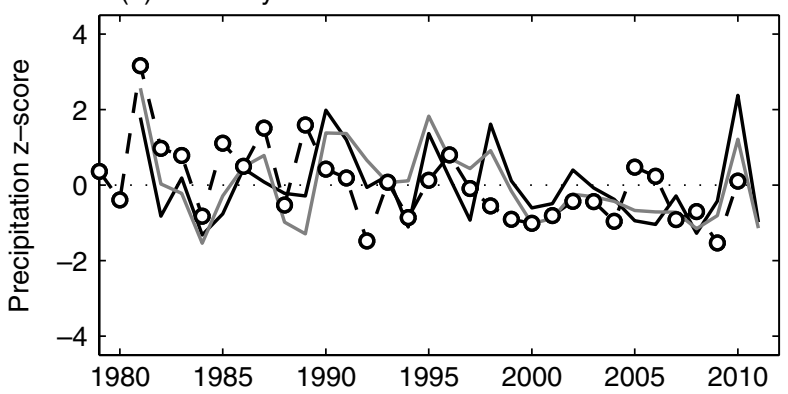

(c) Oct-Dec 2010

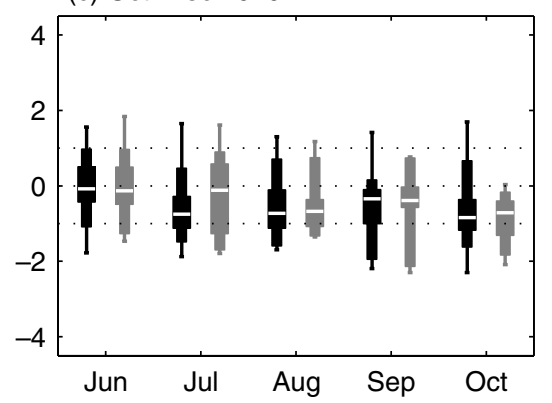

(d) Mar-May 2011

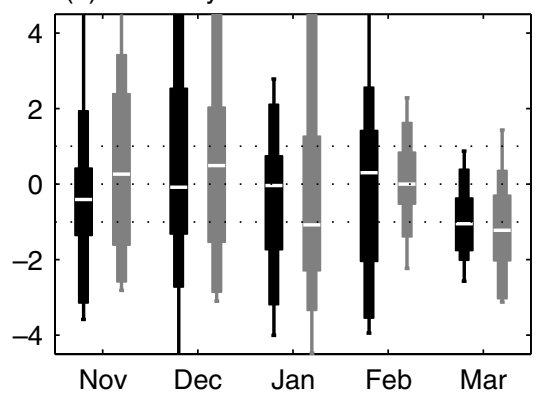

Figure 8. Seasonal precipitation z-scores (removed mean and divided by the standard deviation) of OND (a) and MAM (b) from GPCP22 (dash symbols) and ensemble mean seasonal forecasts of S3 (black) and S4 (gray) for 0 months lag. Seasonal forecasts (S3, black; S4, gray) distribution for OND 2010 (c) and MAM (2011) for different initial forecast dates (see horizontal axis). The boxplots in panels c and d extend from the minimum (whiskers), percentiles 10, 30, 50 (white line), 70, 90 and maximum, while the horizontal dashed lines represent $\pm 1 \mathrm{z}$-score.

[Figure 8(d)]. The OND 2010 forecast anomalies of the precipitation fields (Figure 9) were similar to ERAI and GPCP22 [Figure 3(a) and (b)]. The MAM 2011 spatial patterns of the forecast anomalies (Figure 10) also resemble the ERAI anomalies. In MAM 2011, the seasonal forecasts correctly predicted the dry anomaly over the central western Indian ocean, but failed to predict the westward extension to east Africa (apart from the forecasts starting in March 2011).
Two recent publications discussed the observed drying trend (in particular from 1999 onwards) of the MAM season over east Africa [see GPCP22 in Figure 8(b)]. Williams and Funk (2011) suggested that a westward extension of the ascending branch of the walker circulation, associated with the recent warming in the west Pacific and central Indian Ocean, has caused a trend in the background circulation over the HoA suppressing precipitation in the region. Lyon and DeWitt (2012) linked the 

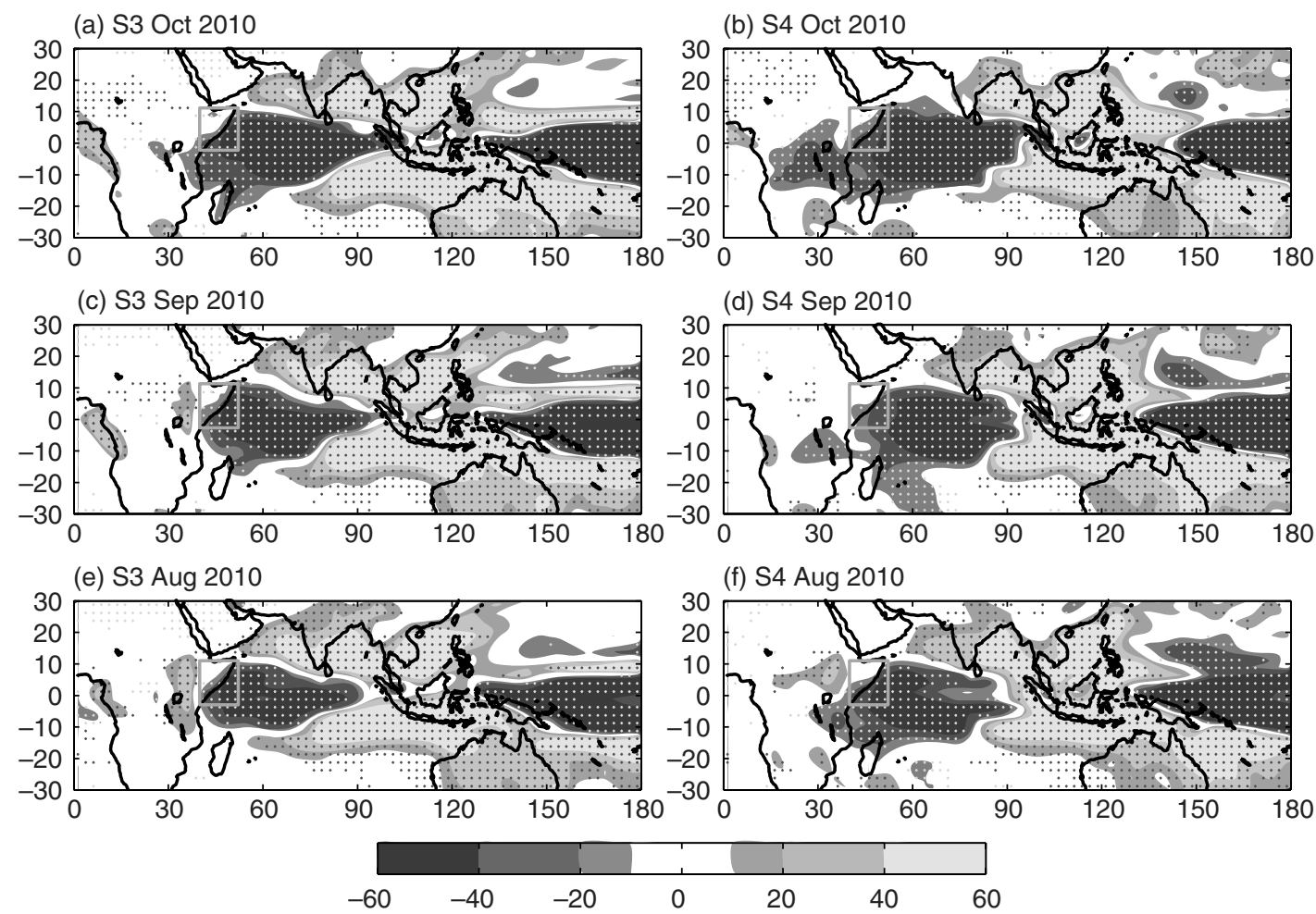

Figure 9. OND 2010 ensembles mean seasonal forecasts (S3 left panels, S4 right panels) of precipitation anomalies (mm) for the forecasts starting in October 2010 (a and b), September 2010 (c and d) and August 2010 (e and f). Dots indicate grid points where 50\% of the ensemble members are bellow the lower tercile or above the upper tercile. Base climatology for the anomaly and terciles calculation comes from the hincasts.
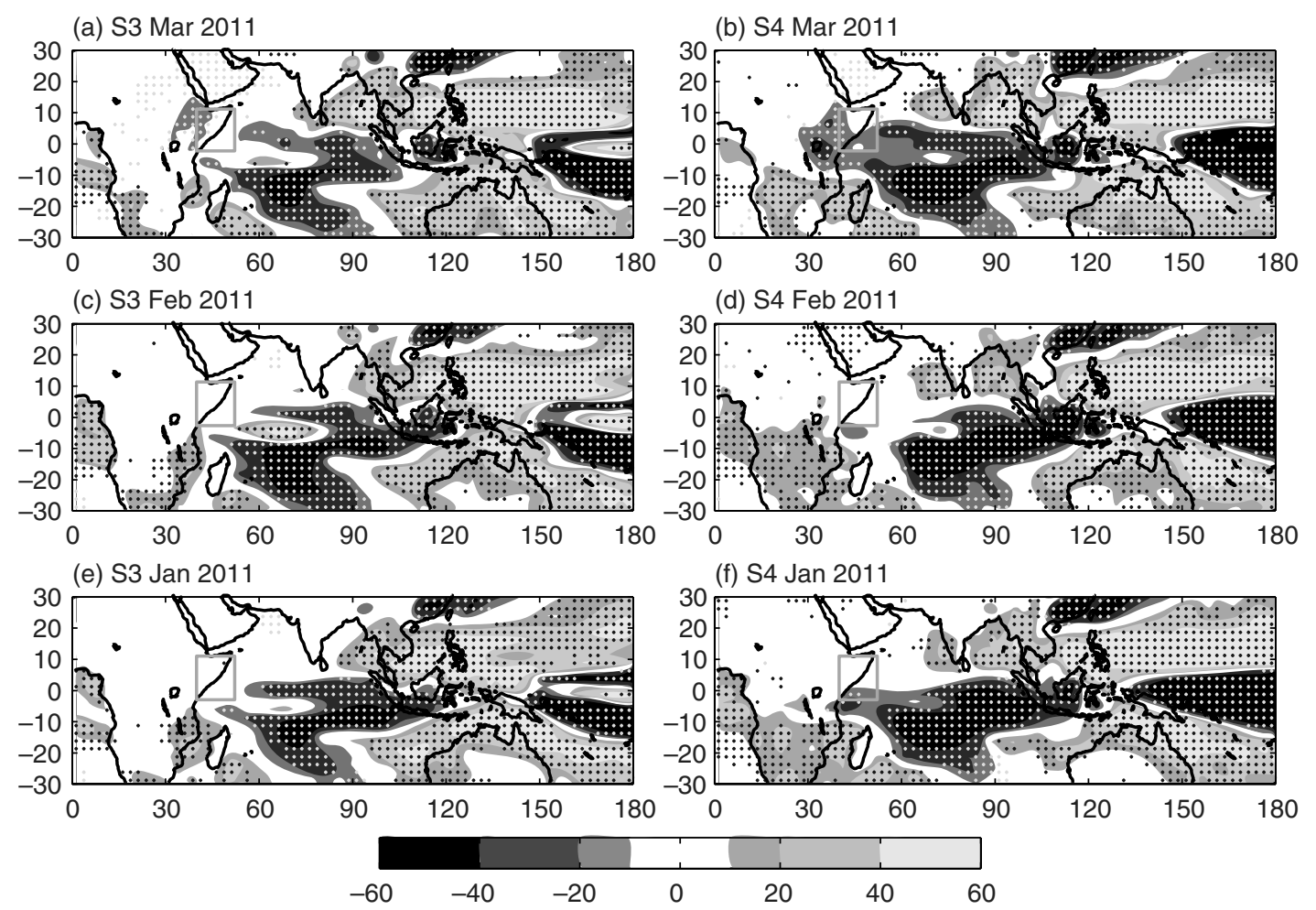

Figure 10. As Figure 9 but for the MAM 2011 ensemble mean seasonal forecasts (S3 left panels, S4 right panels) precipitation anomalies (mm) for the forecasts starting in March 2011 (a and b), February 2011 (c and d) and January 2011 (e and f). 
drying with SSTs in the west tropical Pacific via numeric simulations with a general circulation model (GCM). The MAM precipitation anomalies of GPCP22 for the period 1999-2010, with respect to 1979-1998 [Figure 11(a)], are consistent with the results presented by Lyon and DeWitt (2012), with a drying in east Africa and enhanced rainfall in the northwestern Indian Ocean and central western Pacific. Furthermore, this anomaly pattern resembles the MAM 2011 anomaly in ERAI (Figure 11). The enhanced rainfall, during the last years, over the central western Pacific and northwestern Pacific was forecasted by both $\mathrm{S} 3$ and S4. The drying in east Africa was only detected by S4, with an extension of the dry anomaly over the central Indian Ocean. The rainfall pattern change in S4 is coherent with the GCM simulations carried out by Lyon and DeWitt (2012) with forced SSTs only in the tropical Pacific and climatological SSTs elsewhere. However, the observed precipitation trends over the HoA are more extreme, and extend further south, than those forecasted by S4 [compare Figure 11(a) and (b)]. Furthermore, Figure 11(a) and (b) suggests that the S4 does not accurately simulate how MAM precipitation over the Indian Ocean responds to SST patterns, which was suggested by Williams and Funk (2011) as a possible driver of the suppression of convection over tropical eastern Africa. Our results do not conflict with the finding of Williams and Funk (2011) and Lyon and DeWitt (2012), in terms of the recent trend of precipitation in the HoA, but are inconclusive in terms of the main drivers for this change, that is partially present in S4 and not in S3.

\section{Summary}

In this study, ECMWF products were evaluated in monitoring and forecasting drought conditions during the 2010-2011 event in the HoA.

\section{Monitoring}

The ERAI precipitation anomalies during OND compare well with other observation-based global datasets, noting that these datasets present a large uncertainty in the HoA. This is in line with the findings of Shin et al. (2011). The MAM precipitation interannual variability is poorly captured by ERAI, for reasons yet unexplained. The 2010-2011 drought resulted from a precipitation deficit in both the October-December 2010 and March-May 2011 rainy seasons, and this was captured by ERAI. Soil moisture anomalies of ERAI also identified the onset of the drought condition early in October 2010 with a persistent drought still present in September 2011. This anomaly was also confirmed using the MODIS NDVI.

\section{Forecasting}

The precipitation deficit in October-December 2010 was associated with a strong La Niña event. The ECMWF seasonal forecasts of NINO3.4 predicted the La Niña event
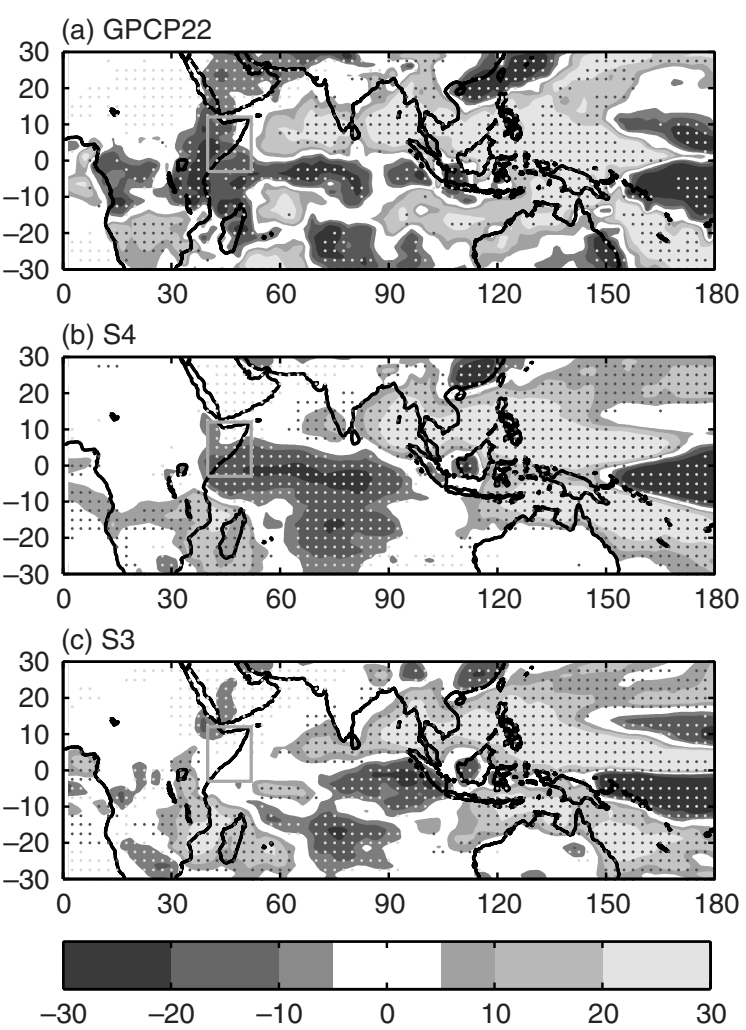

Figure 11. MAM precipitation anomalies averaged over the period 1999-2010 in respect to the period 1979-1998 in GPCP22 (a), and the ensemble mean forecasts (staring in March) of S4 (b) and S3 (c). Dots represent grid points with statistically significant values $(P<0.1)$.

from June 2010 onwards and also a dry precipitation anomaly for the region from July 2010 onwards. However, the seasonal forecasts for the March-May 2011 season did not predict the anomaly, except for the forecasts starting in March 2011. This is consistent with the findings of Camberlin and Philippon (2002), reporting that the March-May season does not exhibit strong relationships with any large-scale climate anomalies. In general, S4 outperforms S3 in simulating the observed MAM drying in east Africa since 1999 (forecasts starting in March).

\section{Outlook}

Climate scenarios for the 21st century suggest an average increase of precipitation in the HoA region (Paeth et al., 2009; Mariotti et al., 2011) that might result in a decrease of moderate droughts (Burke and Brown, 2008) [a signal also found in soil moisture simulations for the present climate (Sheffield and Wood, 2008)]. However, there are also some indications of an increased variability of rainfall in the future (Wolff et al., 2011), and a recent decline of precipitation during the long-rains (MAM) season. Even with an increase of mean precipitation, the increase of interannual variability as well as social and political conflicts makes this region and its population highly vulnerable to future droughts, thus global monitoring and forecasting of drought, such as that presented 
here, is going to become increasingly important in the future.

\section{Acknowledgements}

We are grateful to Franco Molteni and Dick Dee for encouragement and suggestions that helped to improve the manuscript and Rob Hine for his help with the figures. We acknowledge two anonymous reviewers for their valuable suggestions. The MODIS NDVI data were obtained through the online Data Pool at the NASA Land Processes Distributed Active Archive Center (LP DAAC), USGS/Earth Resources Observation and Science (EROS) Center, Sioux Falls, South Dakota (http://lpdaac.usgs.gov/get_data). This work was funded by the FP7 EU projects DEWFORA (http://www. dewfora.net) and GLOWASIS (http://www.glowasis.eu).

\section{References}

Albergel C, De Rosnay P, Balsamo G, Isaksen L, Munoz Sabater J. 2011. Soil moisture analyses at ECWMF: evaluation using global ground-based in situ observations. ECMWF Technical Memorandum 651: 23 .

Anderson D, Stockdale T, Balmaseda M, Ferranti L, Vitart F, Molteni F, Doblas-Reyes FJ, Mogensen K, Vidard A. 2007. Development of the ECMWF seasonal forecast System 3, ECMWF Technical Memorandum 503: 56.

Blunden J, Arndt DS, Baringer MO. 2011. State of the climate in 2010. Bulletin of the American Meteorological Society 92(6): S1-S236, DOI: 10.1175/1520-0477-92.6.s1.

Burke EJ, Brown SJ. 2008. Evaluating uncertainties in the projection of future drought. Journal of Hydrometeorology 9(2): 292-299, DOI: 10.1175/2007jhm929.1.

Camberlin P, Janicot S, Poccard I. 2001. Seasonality and atmospheric dynamics of the teleconnection between African rainfall and tropical sea-surface temperature: Atlantic vs. ENSO. International Journal of Climatology 21(8): 973-1005, DOI: 10.1002/joc.673.

Camberlin P, Philippon N. 2002. The east African March-May rainy season: associated atmospheric dynamics and predictability over the 1968-97 period. Journal of Climate 15(9): 1002-1019, DOI: 10.1175/1520-0442(2002)015<1002:teammr >2.0.co;2.

Dee DP, Uppala SM, Simmons AJ, Berrisford P, Poli P, Kobayashi S, Andrae U, Balmaseda MA, Balsamo G, Bauer P, Bechtold P, Beljaars ACM, van de Berg L, Bidlot J, Bormann N, Delsol C, Dragani R, Fuentes M, Geer AJ, Haimberger L, Healy SB, Hersbach H, Hólm EV, Isaksen L, Kållberg P, Köhler M, Matricardi M, McNally AP, Monge-Sanz BM, Morcrette JJ, Park BK, Peubey C, de Rosnay P, Tavolato C, Thépaut JN, Vitart F. 2011. The ERAInterim reanalysis: configuration and performance of the data assimilation system, Quarterly Journal of the Royal Meteorological Society 137(656): 553-597, DOI: 10.1002/qj.828.

Dutra E, Viterbo P, Miranda PMA. 2008. ERA-40 reanalysis hydrological applications in the characterization of regional drought. Geophysical Research Letters 35: L19402, DOI: 19410.11029/ 12008 GL035381.

Haile M. 2005. Weather patterns, food security and humanitarian response in sub-Saharan Africa. Philosophical Transactions of the Royal Society B-Biological Sciences 360(1463): 2169-2182, DOI: 10.1098/rstb.2005.1746.

Hersbach H. 2000. Decomposition of the continuous ranked probability score for ensemble prediction systems. Weather and Forecasting 15(5): 559-570, DOI: 10.1175/1520-0434(2000)015<0559:dotcrp > 2.0.co;2.

Huete A., Didan K, Miura T, Rodriguez EP, Gao X, Ferreira LG. 2002. Overview of the radiometric and biophysical performance of the MODIS vegetation indices. Remote Sensing of Environment 83: $195-213$.

Huffman GJ, Adler RF, Bolvin DT, Gu G. 2009. Improving the global precipitation record: GPCP Version 2.1. Geophysical Research Letters 36(17): L17808, DOI: 10.1029/2009g1040000.

Huffman GJ, Bolvin DT, Adler RF. 2011. GPCP Version 2.2 Combined Precipitation Data set., WDC-A, NCDC, Asheville, NC. Data set accessed October 2011. Available at http://www.ncdc.noaa.gov/ oa/wmo/wdcamet-ncdc.html.

Janowiak JE, Xie P. 1999. CAMS-OPI: a global satellite-rain gauge merged product for real-time precipitation monitoring applications. Journal of Climate 12(11): 3335-3342, DOI: 10.1175/1520-0442 (1999)012<3335:coagsr $>2.0 . c 0 ; 2$.

Loewenberg S. 2011. Humanitarian response inadequate in Horn of Africa crisis. The Lancet 378(9791): 555-558.

Lyon B, DeWitt DG. 2012. A recent and abrupt decline in the east African long rains. Geophysical Research Letters 39(2): L02702, DOI: $10.1029 / 2011 \mathrm{~g} 1050337$.

Mahfouf JF, Viterbo P, Douville H, Beljaars ACM, Saarinen S. 2000. A revised land-surface analysis scheme in the integrated forecasting system. ECMWF Newsletter 88: 8-13. (Available from ECMWF, Shinfield Park, Reading, Berkshire RG12 19AX, United Kingdom).

Mariotti L, Coppola E, Sylla MB, Giorgi F, Piani C. 2011. Regional climate model simulation of projected 21 st century climate change over an all-Africa domain: Comparison analysis of nested and driving model results. Journal of Geophysical Research 116(D15): D15111, DOI: 10.1029/2010jd015068.

Mitchell TD, Jones PD. 2005. An improved method of constructing a database of monthly climate observations and associated highresolution grids. International Journal of Climatology 25(6): 693-712.

Molteni F, Stockdale T, Balmaseda M, Balsamo G, Buizza R, Ferranti L, Magnunson L, Mogensen K, Palmer T, Vitart F. 2011. The new ECMWF seasonal forecast system (System 4), ECMWF Technical Memorandum 656: 49.

Nicholson SE, Selato JC. 2000. The influence of La Nina on African rainfall. International Journal of Climatology 20(14): 1761 - 1776, DOI: 10.1002/1097-0088 (20001130)20 : 14<1761::aidjoc580>3.0.co; $2-w$.

Paeth H, Born K, Girmes R, Podzun R, Jacob D. 2009. Regional climate change in tropical and northern Africa due to greenhouse forcing and land use changes. Journal of Climate 22(1): 114-132, DOI: $10.1175 / 2008$ jcli2390.1.

Peled E, Dutra E, Viterbo P, Angert A. 2010. Technical Note: Comparing and ranking soil drought indices performance over Europe, through remote-sensing of vegetation. Hydrology and Earth System Sciences 14(2): 271-277, DOI: 10.5194/hess-14-271-2010.

Rudolf B, Schneider U. 2005. Calculation of Gridded Precipitation Data for the Global Land-Surface using in-situ Gauge Observations. Proceeding of the 2nd Workshop of the International Precipitation Working Group IPWF, Monterey October 2004, EUMETSAT, ISBN 92-9110-070-6, ISSN 1727-432×, 231-247.

Schneider U, Becker A, Meyer-Christoffer A, Ziese M, Rudolf B. 2011. Global Precipitation Analysis Products of the GPCC., Global Climatology Centre (GPCC), DWD, Internet Publication, 1-13.

Sheffield J, Wood EF. 2008. Global trends and variability in soil moisture and drought characteristics, 1950-2000, from observationdriven simulations of the terrestrial hydrologic cycle. Journal of Climate 21(3): 432-458, DOI: $10.1175 / 2007$ jcli1822.1.

Shin D-B, Kim J-H, Park H-J. 2011. Agreement between monthly precipitation estimates from TRMM satellite, NCEP reanalysis, and merged gauge-satellite analysis. Journal of Geophysical Research 116(D16): D16105, DOI: 10.1029/2010jd015483.

Stockdale, T., and Coauthors, 2011. ECMWF seasonal forecast system 3 and its prediction of sea surface temperature. Climate Dynamics 37(3): 455-471, DOI: 10.1007/s00382-010-0947-3.

Williams A, Funk C. 2011. A westward extension of the warm pool leads to a westward extension of the Walker circulation, drying eastern Africa. Climate Dynamics 37(11): 2417-2435, DOI: 10.1007/s00382-010-0984-y.

Wolff C, Haug GH, Timmermann A, Damste JSS, Brauer A, Sigman DM, Cane MA, Verschuren D. 2011. Reduced Interannual Rainfall Variability in East Africa During the Last Ice Age. Science 333(6043): 743-747, DOI: 10.1126/science.1203724.

Xie P, Arkin PA. 1997. Global precipitation: a 17 year monthly analysis based on gauge observations, satellite estimates, and numerical model outputs. Bulletin of the American Meteorological Society 78(11): 2539-2558, DOI: 10.1175/1520-0477 (1997)078<2539:gpayma>2.0.co;2. 